\title{
A peculiar faunivorous metatherian from the early Eocene of Australia
}

\author{
Robin M.D. Beck \\ Acta Palaeontologica Polonica 60 (1), 2015: 123-129 doi: http://dx.doi.org/10.4202/app.2013.0011
}

I describe Archaeonothos henkgodthelpi gen. et. sp. nov., a small (estimated body mass 40-80 g) tribosphenic metatherian from the early Eocene Tingamarra Fauna of southeastern Queensland, Australia. This taxon, known only from a single isolated upper molar (M2 or M3) is characterised by a very distinctive combination of dental features that, collectively, probably represent faunivorous adaptations. These include: a straight, elevated centrocrista; a metacone considerably taller than the paracone; a wide stylar shelf ( $\sim 50 \%$ of the total labiolingual width of the tooth); reduced stylar cusps; a long postmetacrista; a small and anteroposteriorly narrow protocone; an unbasined trigon; and the absence of conules. Some of these features are seen in dasyuromorphians, but detailed comparisons reveal key differences between $A$. henkgodthelpi and all known members of this clade. A. henkgodthelpi also predates recent molecular estimates for the divergence of crown-group Dasyuromorphia. Similar dental features are seen in a number of other metatherians, including the South American sparassodonts, Wirunodon chanku from the ?middle-late Eocene Santa Rosa local fauna of Peru, and Kasserinotherium tunisiense from the early Eocene Chambi fauna of Tunisia, although whether $A$. henkgodthelpi is closely related to any of these taxa is unclear based on available evidence. I therefore refer $A$. henkgodthelpi to Metatheria incertae sedis. Potential relatives of $A$. henkgodthelpi are unknown from any other Australian fossil deposit.

Key words: Mammalia, Metatheria, Marsupialia, Sparassodonta, Eocene, Tingamarra Fauna, Australia.

Robin M.D. Beck [r.m.d.beck@salford.ac.uk], School of Environment \& Life Sciences, Room G48, Peel Building, University of Salford, Salford M5 4WT, UK; and School of Biological, Earth and Environmental Sciences, University of New South Wales, Sydney, NSW 2052, Australia.

This is an open-access article distributed under the terms of the Creative Commons Attribution License (for details please see creativecommons.org), which permits unrestricted use, distribution, and reproduction in any medium, provided the original author and source are credited. 
Fof Full text $(207.2 \mathrm{kB})$ 